\title{
COMO A SERVICIFICAÇÃO ESTÁ ASSOCIADA À
}

ECONOMIA

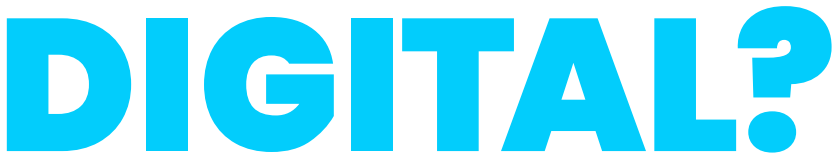

Jorge Arbache

Tempos atrás, fomos ensinados que a contribuição do setor de serviços para a economia estava associada ao estágio de desenvolvimento econômico. Mas o tempo passou e os serviços se tornaram dominantes até mesmo nos países em desenvolvimento, o que indica um forte processo de servicificação geral das economias. De fato, observa-se há muito um contínuo e crescente aumento dos serviços no PIB, transformação que está relacionada a mudanças nas preferências dos consumidores, urbanização, mudanças demográficas e outros fatores estruturais.

Mas houve um grande salto na servicificação nas décadas recentes decorrente do desenvolvimento de tecnologias digitais e de comunicação, tais como a internet e as plataformas digitais. Esse salto viria a permitir que muitos serviços deixassem de ser fornecidos apenas localmente para se tornarem transacionáveis até mesmo internacionalmente. Essa mudança crítica viabilizaria o desenvolvimento de toda uma nova geração de modelos de negócios, que miravam no outsourcing e na globalização como estratégias de redução de custos e aumento de eficiência, incremento de competitividade e estreitamento da relação com os mercados.

Este texto explora a inter-relação entre a servicificação e as tecnologias digitais e suas implicações para as empresas e para as economias.

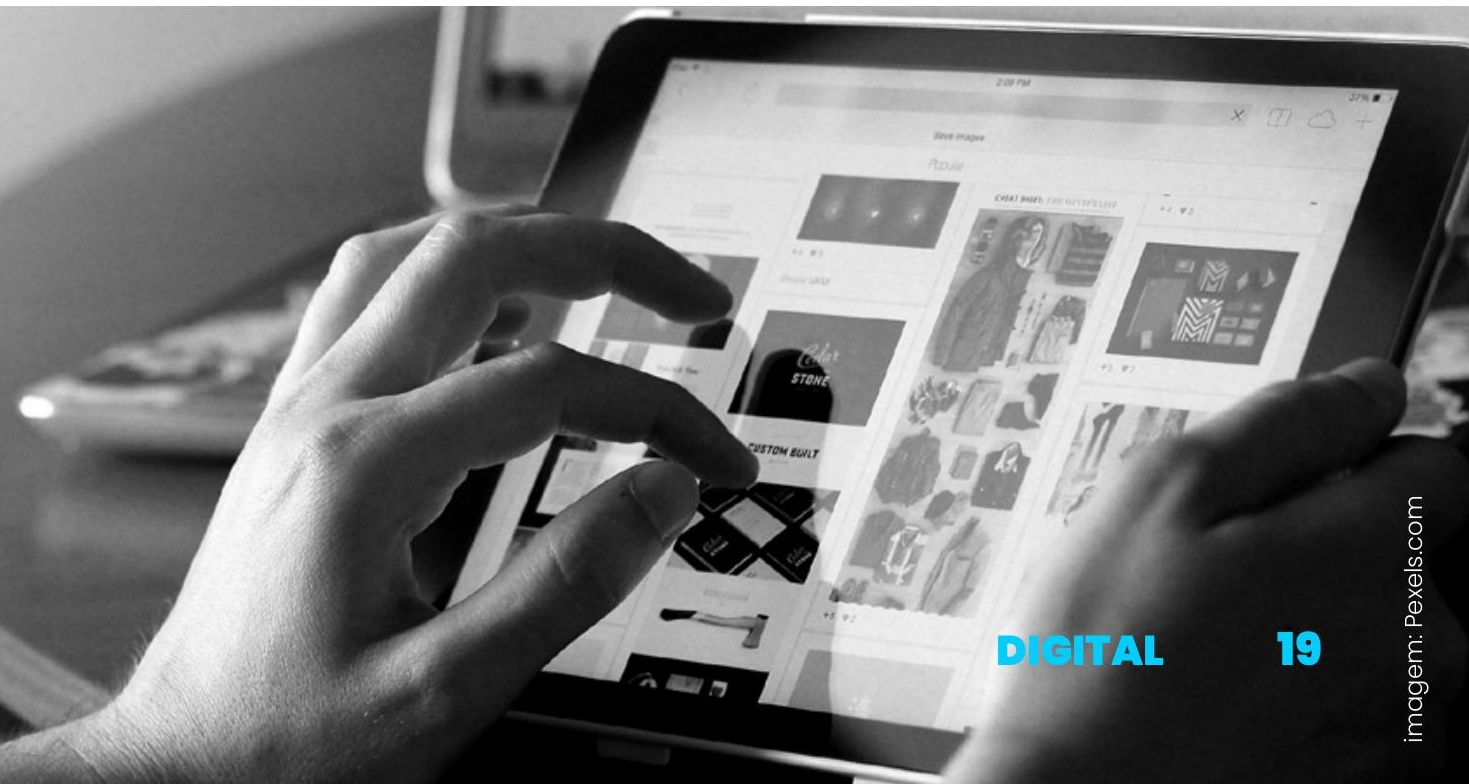




\section{SERVICIFICAÇÃO E TECNOLOGIAS DIGITAIS}

As tecnologias digitais e de comunicação estão viabilizando profundas transformações de cadeias de produção e abastecimento e de relacionamento das empresas com os seus provedores e clientes, possibilitando a gestão e o monitoramento em tempo real, o just in time e a constituição de cadeias globais de valor (CGV). Essas tecnologias também estão permitindo que atividades de gestão e backoffice passem a ser globalizadas, por meio de ferramentas tecnológicas e de comunicação e colaboração remota.

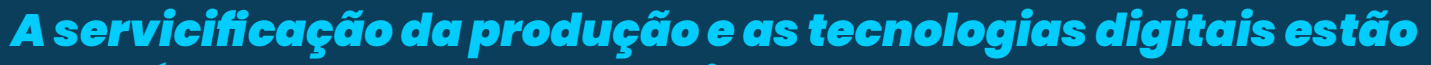
também levando a que parte importante e erescente do valor adicionddo pela indústria e outros setores se deva aos serviços. Incorporaçä̊ de serviços a os bens por meio do outsoureing - serviços vendidos em conjunto com os bens e serviços que vicbilizem o funcioncmento des cadeias de valor - jä́ responde, em muitos cases, a mais de $60 \%$ do valor adicionado de segmentos industricis.

Ali estão incluídas atividades como pesquisa e desenvolvimento, marketing, logística e distribuição, manutenção, financiamento e serviços de pagamentos, back office, plataformas de e-commerce, pós-vendas e suporte ao cliente e tantas outras etapas do ciclo.

As empresas manufatureiras passariam não apenas a incorporar serviços aos produtos por meio do outsourcing, mas a vender serviços como parte do que comercializam - pense no modelo de negócios de fabricantes de turbinas de aviões, que as comercializam não como um bem final, mas como parte de um "pacote de serviços" que inclui serviços de empuxo e mobilidade pay-per-use, serviços de manutenção, monitoramento, leasing e seguros.

Mas algo mais ainda passaria com o advento de tecnologias de produção fortemente intensivas em tecnologias digitais, tais como robôs e impressoras 3D, e tecnologias digitais de gestão da operação, que permitiriam que as empresas pudessem produzir e coletar enormes quantidades de dados associados ao desenvolvimento, produção e comercialização. O big data e outras tecnologias ganhariam, então, centralidade e as empresas passariam a utilizá-los cada vez mais no desenvolvimento de produtos e serviços, na diferenciação de produtos, na identificação de novas oportunidades de negócios, na identificação de padrões e mudanças, nas preferências de cada mercado, bem como nos desenhos e ajustes de estratégias mercadológicas e de interações com os stakeholders. 


\section{QUAL SERVICIFICAÇÃO?}

Com o salto da servicificação, estamos aprendendo não só que a contribuição, mas, também, a estrutura e a composição do setor de serviços importam. Economias mais avançadas têm mais elevada porção de serviços B2B (business-to-business), em que estão incluídas as tecnologias digitais voltadas para os negócios, enquanto economias menos avançadas têm mais elevada porção de serviços B2C (business-to-consumer), em que estão incluídas tecnologias digitais voltadas para o consumidor final. Mas a composição dos serviços B2B também importa em razão das distintas destinações e funções daqueles serviços.

Outra coisa que também estamos aprendendo é que o perfil dos serviços B2B oferecidos reverbera nas vantagens competitivas e na produtividade agregada da economia, já que as distintas atividades de serviços têm produtividades bastante diferentes. Em geral, serviços B2C têm produtividade menor que os B2B e, entre esses, serviços convencionais, como logística e seguros, têm produtividade normalmente bem menor que os serviços de diferenciação de produtos e agregação de valor, como $P \& D$, marketing e marcas.

\section{DE CADEIAS GLOBAIS PARA RECIONAIS}

A servicificação e as novas tecnologias digitais de produção estão viabilizando a customização da produção em nível regional e até local. De fato, aquelas tecnologias estão reduzindo a importância da escala e da arbitragem de custos do trabalho como fatores de competitividade e de localização geográfica de investimentos, levando a mudanças sem precedentes - pense nos tênis que já podem ser feitos sob medida por impressoras 3D a preço acessível ou na produção robotizada de produtos têxteis. Tudo isto está viabilizando o reshoring ou o retorno de plantas industriais antes operando em países em desenvolvimento para países avançados.

De fato, evidências empíricas já mostram que as chamadas Cadeias Globais de Valor (CGV) estão passando por um processo de franca transformação rumo à regionalização.

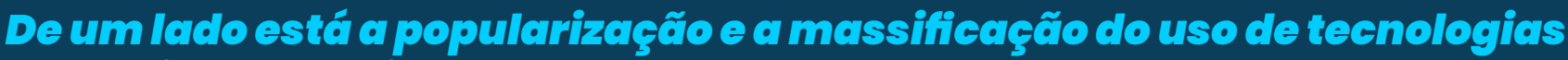
produtivas sofisticadas e poupadoras de mão de obra. De outro lado está a erescente import̂̂neị des serviçes B23 no valor agregedo.

Assim, se o salto da servicificação facilitou e estimulou a formação e a consolidação de CGV, uma segunda onda de mudanças e avanços tecnológicos estaria agora estimulando a regionalização da produção. 


\section{QUAIS SERVIÇOS?}

Estatísticas mostram que os serviços já contribuem com 83\% do PIB dos Estados Unidos, enquanto em países como Argentina, Brasil e México (ABM) os serviços contribuem, em média, com 65\% - no Brasil, são 73\%. Embora a parcela dos serviços B2B no PIB seja bem maior nos Estados Unidos, é na composição que está a maior diferença. Nos Estados Unidos, 53\% dos serviços B2B são serviços convencionais, como logística e manutenção, e $47 \%$ são serviços de agregação de valor e diferenciação de produtos. Nos ABM, são $70 \%$ e $30 \%$, respectivamente.

Aquela diferença reflete, ao menos em parte, diferenças nas estruturas produtivas e nos perfis da oferta e demanda por serviços. De fato, a indústria manufatureira americana demanda substancialmente mais serviços sofisticados e tecnologias digitais para as suas cadeias de produção, enquanto as cadeias dos ABM demandam relativamente mais serviços convencionais, o que é reflexo dos distintos estágios de desenvolvimento tecnológico e gerencial. Assim, a servicificação e o emprego de tecnologias digitais podem tomar caminhos distintos e ter implicações também distintas em temas importantes como a produtividade, por exemplo.

\section{IMPACTOS NOS PAÍSES}

Considerando a crescente servicificação e o protagonismo das tecnologias e serviços digitais na criação de valor, muitos países passariam a priorizar o desenvolvimento, a gestão e a distribuição de serviços e tecnologias digitais de comunicação, produção e gestão como drivers do crescimento econômico, do desenvolvimento tecnológico, das exportações e do emprego.

Os serviços e as tecnologias digitais trariam consigo uma agenda bastante relevante associada a certificações, protocolos de interconexão e interoperabilidade e padrões técnicos e regulatórios. Tratam-se de sistemas operacionais e de telecomunicações, protocolos técnicos de produção e operação de robôs e máquinas-ferramenta, plataformas digitais de produção industrial e de e-commerce, sistemas de pagamentos, padrões e protocolos técnicos de transporte, comercialização e distribuição de bens e serviços, protocolos de mercados financeiros e de capitais, dentre outros associados, direta ou indiretamente, aos negócios. Essa agenda derivada é vista como central para definir o campo em que se joga o "jogo" e, assim, influenciar os destinos dos negócios. 


\section{Jorge Arbeche}

Vice-presidente do Setor Privado do Banco de Desenvolvimento da América Latina (CAF) e professor de economia da Universidade de Brasília.

Foi Secretário de Assuntos Internacionais do Ministério do Planejamento e Economista-Chefe desse Ministério. Dentre os cargos anteriores incluemse Secretário Executivo do Fundo de Investimento Brasil-China; Assessor Econômico Sênior do Banco Nacional de Desenvolvimento Econômico e Social

- BNDES; Economista Sênior do Banco Mundial; Economista da Organização Internacional do Trabalho; membro do conselho de administração de grandes empresas e bancos; e membro de comitês consultivos de instituições nacionais e internacionais. Arbache é colunista de opinião do Jornal Valor Econômico e tem publicado regularmente trabalhos acadêmicos sobre economia do desenvolvimento e assuntos relacionados. 